\title{
SENTIMIENTOS DE MUJERES GESTANTES AL CONOCER QUE SU HIJO NACERÁ CON ANOMALÍA CONGÉNITA
}

Juan Alberto Carrillo Ortiz, Sandra Milena Cubillos Bermúdez, Sandra Patricia Prada Penagos, Claudia Patricia Salamanca Peña, Mercedes Rátiva Velandia*

\section{Resumen}

El objeto de esta investigación de tipo fenomenológico, es describir los sentimientos percibidos por mujeres gestantes con previo conocimiento de que su hijo nacerá con anomalía congénita, para facilitar una futura y eficaz intervención de enfermería. Se aplicó una entrevista semiestructurada a siete mujeres gestantes atendidas en una institución de tercer nivel y después se realizó un taller de retroalimentación. De este modo, se encontró que los sentimientos de mayor aparición fueron la tristeza y el miedo. Se concluyó, que debe existir un equipo interdisciplinario que involucre a la familia y brinde un adecuado apoyo para facilitar el proceso de duelo de dichas madres gestantes.

Palabras Claves: Sentimientos, anomalías congénitas, mujer gestante

\section{Introducción}

El trabajo se realizó con base en las observaciones directas y análisis del grupo investigador, para conocer los sentimientos y dificultades que afrontan las futuras madres al saber que su hijo nacerá con alguna anomalía. Su objetivo fue identificar los sentimientos percibidos por dichas madres.

Hablar o abordar el tema de anomalías congénitas es difícil, pero lo es más aún encontrarse con aquellos sentimientos experimentados por madres gestantes que sabiendo que llevan en su vientre un ser con anormalidades, se hacen responsables de su suerte, acompañadas de dolor, sufrimiento, incertidumbre, nostalgia y para muchas una fija creencia de fracaso.

Este diagnóstico es un impacto que consterna, que altera el equilibrio emocional de la madre, pero que aún así es visto como poco importante y olvidado por la mayoría de los miembros del equipo de salud.

Esta investigación es pertinente, pues por factores ambientales, socioeconómicos, biológicos y culturales,

\footnotetext{
Estudiantes de VII semestre Facultad de Enfermería. Fundación Universitaria de Ciencias de la Salud.

** Este trabajo fue realizado bajo la tutoría de la doctora María José Navarrete, enfermera profesora Depto. Materno Infantíl.
}

las anomalías han incrementado en forma progresiva y hacen que el enfermero, como parte del personal encargado de proteger la salud, debe estar preparado para un correcto, verídico, acertado y oportuno manejo de dicha situación.

\section{Materiales y métodos}

El presente estudio fue elaborado mediante la aplicación del método fenomenológico realizando una entrevista semiestructurada a siete mujeres gestantes con diagnóstico de anomalía congénita y que asistieron a su control prenatal en una institución de tercer nivel de la ciudad de Bogotá, durante el periodo comprendido entre enero y marzo del año 2002, con previa autorización por medio de un consentimiento informado, para el manejo de dicha información. Las madres fueron seleccionadas por medio de un muestreo no probabilístico y a conveniencia, contactándolas de manera directa durante su control prenatal.

Para el análisis se transcribieron las entrevistas, se identificaron los sentimientos y se agruparon en categorías, las cuales corresponden a estados de afecto del individuo y subcategorías, que corresponden a las emociones propias de cada estado afectivo (Tabla 1). 
Después se dieron a conocer los resultados obtenidos durante un taller de retroalimentación, al que asistieron cuatro de las siete madres y quienes con base en la película titulada «el corazón de un bebé» manifestaron sus experiencias.

\section{Resultados}

La gran mayoría de los problemas que atraviesan los padres y familiares de un recién nacido que nacerá con anomalía, están relacionados principalmente con dos situaciones presentes en estos niños:

- Aspecto físico desagradable, el cual interferirá la interacción entre la madre y el hijo.

- Incapacidad física, que puede llegar a ser una carga para la familia, limitando las actividades sociales, culturales y laborales de los padres.

Los sentimientos que más se presentaron en las madres gestantes entrevistadas fueron la tristeza y el miedo, seguidos por culpa, angustia y dolor. Reacciones como rabia, rechazo, soledad, frustración, decepción, amor y felicidad, presentaron menor incidencia (Tabla 2).

Hay quienes señalan que se manifiesta una emoción sólo cuando lo experimentado por el individuo es desagradable, es decir, cuando surge odio, ira, rencor a vergüenza. En el caso de las sensaciones agradables se habla de sentimiento. No se puede asegurar que esta diferenciación

\begin{tabular}{ll}
$\begin{array}{l}\text { Tabla I. Categorias de variables, estados } \\
\text { de ánimo y emociones propias de cada uno }\end{array}$ \\
\hline CATEGORÍA & SUBCATEGORÍA \\
\hline FRUSTRACIÓN & Angustia \\
& Frustración \\
& Depresión \\
& Rabia; ira \\
& Rechazo \\
\hline DEPRESIÓN & Tristeza \\
& Soledad \\
& Culpa \\
& Dolor \\
& Miedo \\
\hline JÚBILO & Amor \\
& Felicidad \\
\end{tabular}

sea cierta. Es por ello, que al hablar aquí de sentimientos se hará de forma generalizada incluyendo los agradables y desagradables por igual.

En todo caso, sea de la manera que fuere, los sentimientos están siempre presentes en el ser humano y requieren de un estímulo exterior para poder sentirlos e interiorizarlos en el intelecto. Es así como los sentimientos de estas madres gestantes se mueven entre extremos opuestos (placer - dolor, amor - odio, esperanza - desesperanza), son profundos o superficiales, perdurables en el tiempo y se distinguen por sus notas de gran intensidad y momentaneidad.

El contenido emocional de estas mujeres gestantes será feliz o infeliz dependiendo de la medida en que esa persona haya rechazado el misticismo mediante la aceptación de la absoluta responsabilidad de comprender y afrontar la realidad con honestidad.

La tristeza presentada en cinco de las madres entrevistadas nace de sentirse herida por una palabra, un episodio o un hecho que proviene del mundo exterior; por pudor esconden cuidadosamente el disgusto sufrido y caen en la tristeza.

Esta se manifiesta comouna disminución de la actividad corporal que puede confundirse con hipocondría, es abandono progresivo del cuerpo y la postración total del ánimo. También nace de una aflicción que la precede, abatimiento que nos inclina, una pasión letárgica que nos deja

\section{Tabla 2. Aparición de los}

sentimientos en las diferentes entrevistas

\section{SENTIMIENTO}

FRECUENCIA

$\begin{array}{ll}\text { Tristeza } & 5 \\ \text { Miedo } & 5 \\ \text { Culpa } & 4 \\ \text { Angustia } & 3 \\ \text { Dolor } & 3 \\ \text { Rabia; ira } & 2 \\ \text { Rechazo } & 2 \\ \text { Soledad } & 2 \\ \text { Frustración } & \text { I } \\ \text { Decepción } & \text { I } \\ \text { Amor } & \text { I } \\ \text { Felicidad } & \text { I }\end{array}$


adinámicos sin querer hacer nada, en un reposo inerte: así sufrimos estados sin horizontes, días sin sol, rehuyendo del diálogo y contacto humano, o vivimos tensamente exaltados para ocultar la tristeza que padecemos.

En el fondo, la tristeza de estas madres guarda la nostalgia de una felicidad perdida que orienta al futuro a revivir ese pasado y los sueños e ilusiones de ellas se ven truncados por sucesos que le son difíciles de aceptar.

Es de anotar también que dicha tristeza no presentó la misma intensidad en todas las madres entrevistadas. Dentro de los factores que influyen se encuentran:

- Tipo de anomalía congénita.

- Nivel sociocultural y educativo de la madre.

- Manera de informar el diagnóstico.

El miedo es una reacción de sobresalto ante un estímulo inesperado, se relaciona con dos componentes que interactúan estrechamente hasta confundirse: uno propio de la esfera afectiva intelectual y otro ligado al dominio instintivo. Como consecuencia de ello, el miedo podría ser visto como un estado que resulta de la unión de una reacción afectiva de intensidad variable con manifestaciones neurovegetativas más o menos importantes, que repercuten internamente en los actos del sujeto.

El miedo confiere a estas madres una sensación de tensión nerviosa que les permite protegerse o desarrollar tendencias a la acción evasiva. La motivación de protección se manifiesta en forma típica mediante la huida y retirada al estímulo, evidente en ellas.

Por lo tanto, el miedo puede activar los esfuerzos de afrontamiento y facilitar el aprendizaje de habilidades adaptativas. Sin embargo, el afrontamiento y el aprendizaje de estas habilidades requiere apoyo, tiempo de duelo y compañía de una persona dispuesta a escuchar, aspectos importantes y al mismo tiempo relativos en cada una de las madres entrevistadas, pues mientras que algunas cuentan con apoyo y compañía, otras carecen de ellos. Pero lo que sí coincide es que todas hasta ahora comienzan su proceso adaptativo debido a que el tiempo transcurrido entre la noticia del diagnóstico y el momento de la entrevista era corto.

All igual que sucede con la tristeza, el miedo tiene diferentes causas, algunas madres entrevistadas temen que la anomalía de su hijo sea demasiado grave, otras al rechazo de la sociedad, pero sea cual fuere la causa, el sentimiento es el mismo.

En las entrevistas realizadas los sentimientos de culpa ocupan una parte importante de su experiencia, ya que en muchas ocasiones tiene que ver con la historia familiar y de relación de la mujer con la gestación. Muchas de ellas inician una búsqueda del por qué sucede este evento y al no encontrar respuesta comienzan a relacionar factores, como no haber seguido de manera estricta los controles prenatales, o haber tomado medicamentos en alguna etapa del embarazo, entre otros. Pensar que son responsables de la anomalía con la que va a nacer su hijo despierta en ellas el sentimiento de culpa.

Muchas madres tienen este sentimiento en el momento de la noticia pero al recibir información concreta y apta para ellas, disminuye en intensidad al comprender que en algunos casos no son responsables de la anomalía; pero en circunstancias diferentes en donde el nivel social y cultural de la persona es bajo, no perciben este sentimiento porque no comprenden la magnitud del daño y por el contrario creen que es un regalo de Dios.

La ansiedad se presentó en tres de las siete entrevistadas. Se define como un estado desagradable, vivenciado como inquietud, sentimiento de amenaza o temor indefinido, sin que exista una causa desencadenante en el medio ambiente; en muchos de los casos surge del conflicto de motivos donde el individuo puede llegar incluso a experimentar infelicidad. Su origen es endógeno y el factor etiológico parte de los conflictos elaborados por el yo. Este sentimiento permite que el individuo sea capaz de identificar la situación, pero en realidad es una amenaza a sí mismo, se refiere a la inquietud enredada en la situación y suele manifestarse durante un tiempo por cambios conductuales y fisiológicos

Dicho estado se caracteriza por sentimientos de tensión, aprensión, inseguridad, así como autovaloraciones negativas que se manifiestan en las respuestas de las mujeres gestantes con previo conocimiento de que su hijo nacerá con anomalía congénita.

En esta investigación, se considera la angustia como una reacción normal de las mujeres gestantes que aparece ante una situación de estrés difícil de comprender, 
como es llevar en su vientre un niño con anomalía congénita. Sin embargo, estas reacciones pueden llegar a ser patológicas en un momento dado.

El dolor se ha descrito psicológicamente como una experiencia cuya dimensión sólo es definible por quien lo sufre, considerado como una experiencia ajena a quien no lo siente. La sensación dolorosa solo es posible describirla en los términos en que la percepción de la madre lo refleja.

Tal es el caso de las mujeres gestantes, quienes en sus aparentes respuestas verbales, cortas y secas, ocultan en su contenido un sufrimiento silencioso y doloroso, una falta de apoyo y una desconocida realidad a la que tendrán que enfrentarse con el nacimiento de ese pequeño e indefenso ser, situación que puede generar sentimientos mucho más fuertes y difíciles de imaginar.

Por consiguiente, a la subjetividad de la experiencia se añade ahora el contexto cultural y social que determina las manifestaciones que se producen ante un estimulo orgánico generador del dolor.

La rabia es también la emoción potencialmente más peligrosa ya que su propósito funcional es el de destruir las barreras en el ambiente. Así mismo, desde una perspectiva evolutiva la rabia moviliza la energía hacia la autodefensa, una actitud caracterizada por vigor, fuerza y resistencia. Por esta razón, la rabia puede considerarse un fenómeno ambivalente.

La rabia presentada por dos de las madres entrevistadas se dirige hacia el equipo de salud, por la manera como se les dió la noticia. Algunas afirman que quien les comunica el diagnóstico lo hace de una manera natural para él, pues ya esta familiarizado con este tipo de problemas, pero olvida que para la madre es la primera vez que lo escucha.

El rechazo aparece al enterarse de que su hijo no es como ella lo concebía en su mente. Aquí es importante el concepto que tenga de las personas "anormales" antes de enterarse de la noticia. Otra causa del rechazo es el grado y la magnitud de la malformación; se observó que existe este sentimiento en casos de anomalías de alta gravedad.

Se encontró soledad en dos de las madres entrevistadas, refieren que aunque estén rodeadas por su familia se sienten solas, ya que no tienen con quién expresar sus sentimientos; influye en gran medida el hecho de tener a alguien acompañándolas en el momento de recibir el diagnóstico.

La frustración apareció en una madre; es posible que haya influido el hecho de no ser una gestación planeada, se encuentra en la dualidad que sus metas ya no se cumplirán, lo cual genera un alto grado de insatisfacción.

Los sentimientos de amor y felicidad aparecieron en aquellas madres que han tenido un mayor tiempo de proceso de duelo; por otra parte, influyó lo que significa un hijo para ellas. Manifiestan que por fortuna las anomalías no son tan limitantes y por esto siente felicidad. Una de las madres refiere que el amor sucumbe a toda clase de adversidad.

Los anteriores resultados dan a conocer la necesidad de la intervención de un equipo interdisciplinario que permita un seguimiento a estas madres con el fin de evitar complicaciones que pueden aparecer por la falta de apoyo, ya que en la actualidad se encuentran solas y a la expectativa de lo que más adelante sucederá. Para ello, es importante que enfermería intervenga brindando apoyo centrado en una sola frase: valor de vivir, valor como algo estimable, precioso valor como coraje y valentía; valor que está en nuestras manos, brindar y enseñar a manejar; es decir, buscar la transdisciplinariedad.

\section{Discusión}

La creciente incidencia de las anomalías congénitas ha llevado a realizar diferentes trabajos sobre el tema. Esta investigación corrobora la aparición de manifestaciones tales como ira y tristeza, que se han encontrado en anteriores estudios, sin embargo, se observan otros sentimientos como miedo, culpa, dolor, angustia, rechazo, frustración, soledad, amor y felicidad, que en conjunto describen la situación de las madres gestantes con diagnóstico de anomalía congénita y al igual que en las demás investigaciones justifican la importancia del apoyo e intervención del profesional de enfermería, fundamentado en las manifestaciones expresadas por ellas durante el estudio.

El sentimiento nace de una comunicación objetiva, de la recíproca dependencia humana e implica que al 
sentir a los otros se siente uno mismo. Son la suprema forma de objetivarse; son subjetivos porque los vivimos en la interioridad y objetivos al hacer salir a la persona de la clausura interior.

\section{Conclusiones}

- Los sentimientos de tristeza y miedo seguidos por culpa, ansiedad y dolor fueron los de mayor incidencia entre las madres gestantes con diagnóstico de anomalía congénita. La rabia, rechazo, soledad, frustración, decepción, felicidad y amor se presentaron en menor número.

- Se debe involucrar a la familia de la madre gestante con este tipo de problemática, ya que en ocasiones en vez de brindarle apoyo puede llegar a generar en ella sentimientos de culpa.

- El tiempo transcurrido entre el diagnóstico de la anomalía congénita y el momento de la entrevista influye en la aparición de los diferentes sentimientos, lo cual se evidencia unido los «positivos» como amor y felicidad aparecieron solo en las madres entrevistadas que tenían un mayor tiempo de duelo.
- Por lo anterior, se sugiere que enfermería retome su papel, teniendo en cuenta que es el profesional clave y capacitado para la atención de estas madres, quienes viven una situación de estrés y fuerte impacto no sólo en su parte física, sino a nivel biopsicosocial, creando un programa de atención interdisciplinaria que reúna los siguientes aspectos: seguimiento, apoyo psicológico, atención médica, instrucción en los cuidados prenatales y postnatales según la anomalía congénita, y orientación profesional en el proceso de duelo.

\section{Lecturas recomendadas}

- Arias L. E. Marulanda D. M. Medina A. L. Impacto en el diagnóstico prenatal de anomalía congénita en la gestante y su núcleo familiar. Bogotá Universidad Nacional de Colombia 1998.

- Gurmendez C. Teoría de los sentimientos.México: Fondo de Cultura Económica, 1991. p 84.

- Hernández O. D. Entorno Psicológico del recién nacido malformado. Santafé de Bogotá: 1993. p 3-9.

- Mora G. E. Valores humanos y actitudes positivas. Madrid: Mc Graw Hill 1999. p.98-199.

- Reeve J. Motivación y emoción. Madrid: Mc Graw Hill, Madrid 1995, p. 62-94

- Whittaker J O. Psicología. 4 ed. México: 1986 p.229-238.

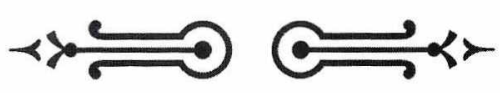

